\title{
Global large herbivore conservation and international law
}

\author{
Arie Trouwborst ${ }^{1}$ (D)
}

Received: 21 May 2019 / Revised: 3 September 2019 / Accepted: 11 September 2019 /

Published online: 25 September 2019

(c) The Author(s) 2019

\begin{abstract}
Large wild herbivore species are important to ecosystems and human societies, but many of them are threatened and in decline. International wildlife treaties have a role to play in arresting and reversing these declines. This paper provides a global overview and analysis of relevant legal instruments and their roles regarding the conservation of the 73 largest terrestrial herbivores, i.e., those with a body mass of $\geq 100 \mathrm{~kg}$. Outcomes reveal both significant positive contributions and shortcomings of the Ramsar Wetlands Convention, the World Heritage Convention, the Convention on International Trade in Endangered Species, the Convention on Migratory Species and its subsidiary instruments, the Convention on Biological Diversity, and a range of regional and bilateral treaties. Maximizing the potential of these treaties, and attaining their objectives regarding the conservation and restoration of large herbivores, requires substantial increases in funding and political will. Even before such game-changing increases occur, however, it remains worthwhile to seek and use the many opportunities that exist within the current international legal framework for enhancing the conservation of the world's largest herbivores.
\end{abstract}

Keywords Convention on International Trade in Endangered Species (CITES) • Convention on Migratory Species (CMS) · Convention on Wetlands of International Importance $\cdot$ Herbivores $\cdot$ International law $\cdot$ World Heritage Convention

\section{Introduction}

The particular vulnerability of large-bodied wild animal species is reflected in the conservation status, population declines and range contractions of many such species (Cardillo et al. 2005; Schipper et al. 2008; Macdonald et al. 2013; Moreno di Marco et al. 2014; Ripple et al. 2014, 2015, 2016). For the world's largest terrestrial herbivores and carnivores, studies have indicated both the crucial ecological role many of these species play-or used to play - and the worrying conservation status of most of them (Macdonald et al. 2013;

Communicated by Dirk Sven Schmeller.

This article belongs to the Topical Collection: Biodiversity legal instruments and regulations.

Arie Trouwborst

a.trouwborst@tilburguniversity.edu

1 Department of Public Law and Governance, Tilburg University, Tilburg, The Netherlands 
Ripple et al. 2014, 2015). Many large herbivores are keystone species or 'ecosystem engineers', shaping the function and structure of landscapes-inter alia by cycling nutrients, dispersing seeds, providing food for predators and scavengers, influencing fire regimes, and providing benefits to mesoherbivores and birds, rodents and insects-and directly benefit people, through various consumptive and non-consumptive uses (Owen-Smith 1989; Danell et al. 2006; Ripple et al. 2015). Significantly, many roles played by large herbivores 'cannot be taken over or compensated for by smaller herbivores' (Ripple et al. 2015, p. 6). Conservation professionals involved in large herbivore (and large carnivore) conservation have called for increased efforts to conserve and restore the remaining populations of these megafauna species, through a comprehensive range of approaches-including international wildlife treaties (Macdonald et al. 2013; Ripple et al. 2016).

Amongst the many approaches that are part of the overall effort to slow down and reverse global biodiversity loss, law can indeed be a significant contributor (Chapron et al. 2017), including international wildlife law (Bowman et al. 2010; Trouwborst et al. 2017a). International wildlife treaties recognize the transboundary nature of many wildlife populations and of some of their threats. They also reflect the notion that biodiversity conservation - including of species that are not transboundary - is a 'common concern of mankind', as the preamble to the 1992 Convention on Biological Diversity (CBD) puts it. A large and perhaps bewildering number and variety of relevant treaties and other legal instruments exists (see, e.g., the selection in Table 1). To help conservation professionals and other stakeholders gauge the actual and potential contribution of international wildlife law, and to critically explore options for maximizing its added value, a useful role appears to be reserved for international law research, preferably in tandem with other relevant disciplines (Freyfogle 2006; Chapron et al. 2017; Cliquet and Decleer 2017; Trouwborst et al. 2017a, b; Macdonald 2019).

Hitherto, such research concerning terrestrial megafauna has predominantly addressed large carnivores and some of the megaherbivores. Species-specific international law analyses regarding large carnivores have focused inter alia on lions Panthera leo (Watts 2016; Trouwborst et al. 2017b; Bauer et al. 2018; Hodgetts et al. 2018), cheetahs Acinonyx jubatus (Nowell and Rosen 2018), leopards Panthera pardus (Trouwborst et al. in press), and ocelots Leopardus pardalis (Kimberley 2017), in addition to an extensive legal literature on gray wolves Canis lupus and other large carnivores in Europe (see, e.g., Epstein 2013; Linnell et al. 2017; Trouwborst 2018). The international law literature on large herbivores includes research regarding hippopotamus Hippopotamus amphibius (Snyder 2015), rhinoceroses (Leader-Williams et al. 2005; Ayling 2013; Coetzee and Couzens 2017; Janssens and Trouwborst 2018), and especially elephants (Glennon 1990; Kidd and Cowling 2003; Couzens 2014; Nollkaemper 2014; Selier et al. 2016; Persaud 2017; Wandesforde-Smith 2016; Jung 2017), with most studies predominantly addressing international trade regulation. Further studies have addressed the role of international law from the perspective of particular issues affecting various megafauna species (carnivores and herbivores), such as international trade (e.g., Wiersema 2013) or border fences (Trouwborst et al. 2016).

For large carnivores, a global analysis published in 2015 assessed the role of international wildlife law with regard to the 31 Carnivora species (except pinnipeds) with an average adult body mass of 15 kilograms or more (Trouwborst 2015, using the same species selection as Ripple et al. 2014). For large herbivores, no such global analysis existed to date, and this paper is intended to provide one.

Of the approximately 4000 terrestrial mammalian herbivore species, 73 have a mean adult body mass of 100 kilograms or more (Ripple et al. 2015). 64\% of these heaviest herbivores currently have a threatened status on the IUCN Red List, and $60 \%$ have declining 


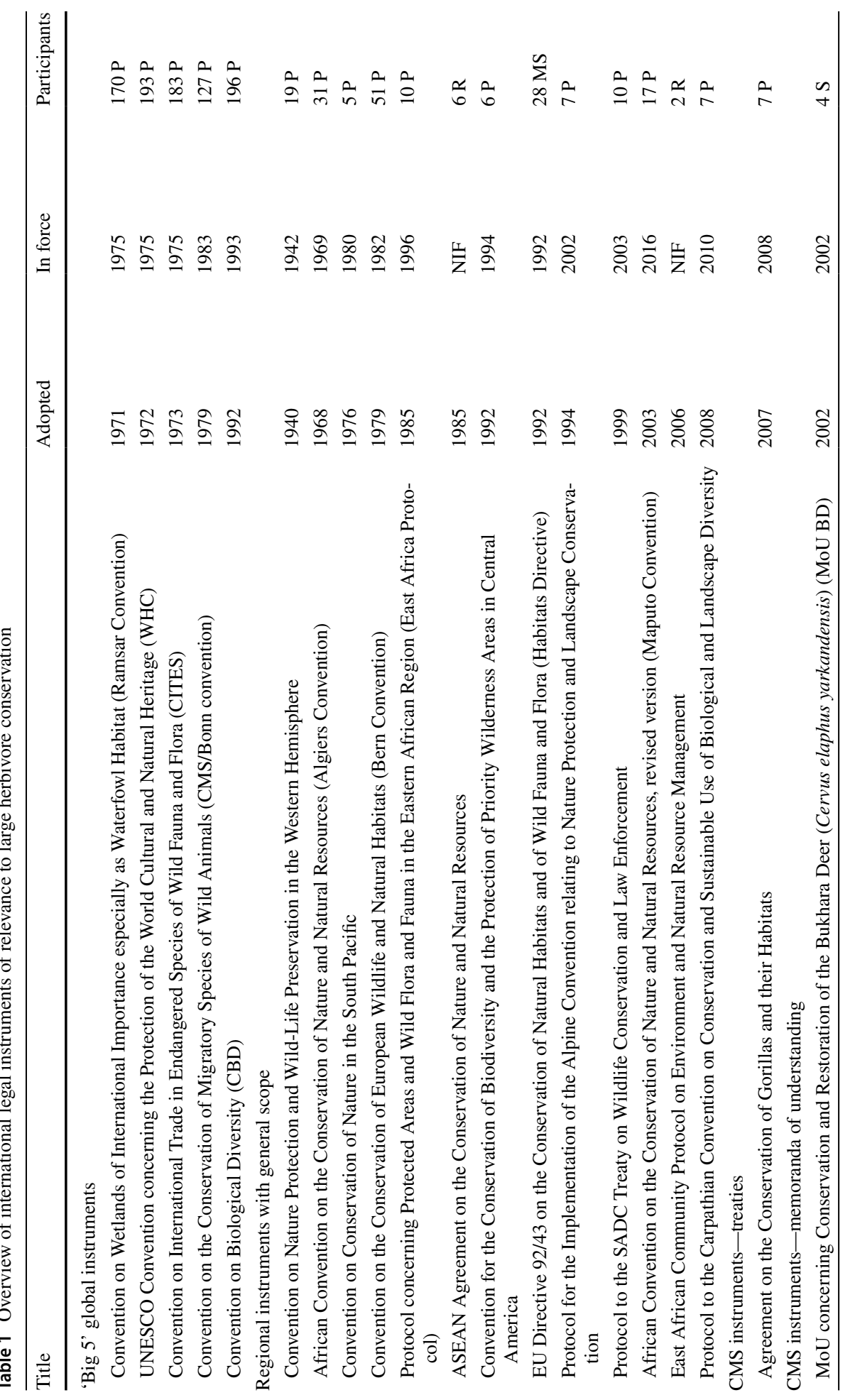




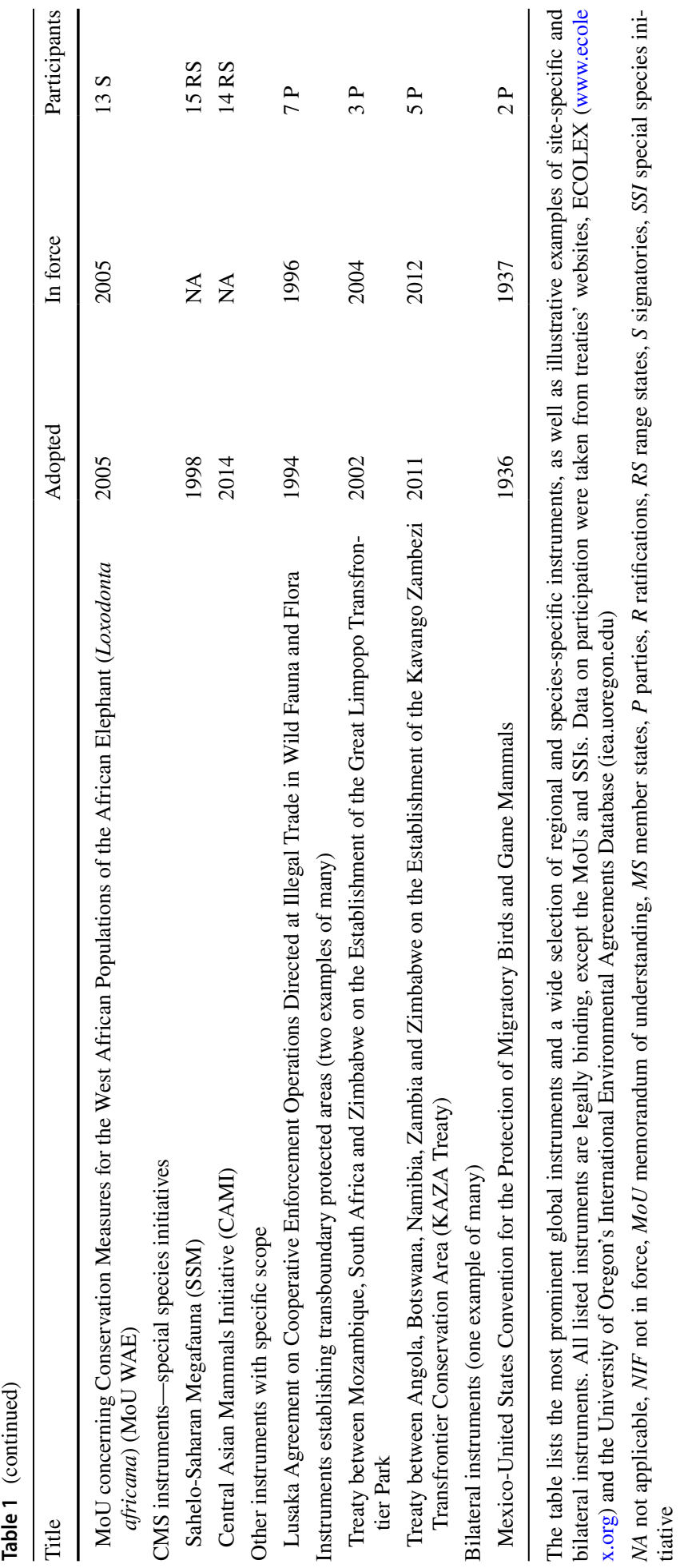


populations (Table 2). Their large size predisposes many such species to be exploited by people and to conflict with them (Macdonald et al. 2013). Principal threats include habitat loss and degradation due to inter alia agricultural expansion, increasing livestock numbers, and deforestation; and unsustainable killing for meat and body parts or because of conflicts (Macdonald et al. 2013; Ripple et al. 2015, 2016). Particular conservation challenges arise from the significant spatial requirements of many large herbivores (Macdonald et al. 2013) and the fact that most of these species, including the great majority of threatened large herbivores, occur in developing countries (Ripple et al. 2015). This state of affairs, in combination with the aforementioned important ecological roles of large herbivores, seems to represent sufficient reason to gauge the actual and potential contribution of international law to the conservation of these species.

Therefore, the analysis below seeks to chart the current international legal landscape applicable to large herbivore conservation by identifying relevant treaties, and to provide a basic assessment of such treaties' contribution to large herbivore conservation to date, of gaps and other shortcomings, and of ways and opportunities to maximize their contribution. An analysis of this breadth can provide little more than a bird's-eye view, but can hopefully serve as a basis or aid for more in-depth analyses, and perhaps render one or two outcomes of practical conservation relevance.

\section{Method}

Standard international law research methodology is used, involving the identification and analysis of relevant treaties and their interpretation according to the rules codified in the 1969 Vienna Convention on the Law of Treaties (e.g., Bowman et al. 2010; Trouwborst et al. 2017a), informed by knowledge on the species concerned and their conservation needs from the conservation biology literature and other relevant disciplines.

The analysis focuses on the 73 terrestrial herbivore species with an average adult body mass of $100 \mathrm{~kg}$ or more (listed in Table 2), which is the same set of species analyzed by Ripple et al. (2015) (the only difference concerns moose, as Ripple et al. treated Eurasian elk Alces alces and moose Alces americanus as separate species, whereas these are presently considered the same species Alces alces on the IUCN Red List). Below, the term 'large herbivores' is used to refer to these 73 species. They represent 11 families, i.e., Elephantidae, Rhinocerotidae, Hippopotamidae, Giraffidae, Bovidae, Camelidae, Tapiridae, Equidae, Cervidae, Suidae, and Hominidae. 65 of them have a body mass between 100 and $1000 \mathrm{~kg}$, the other 8 being the 'megaherbivores' weighing over $1000 \mathrm{~kg}$, i.e., elephants, rhinoceroses and hippopotamus. (The scientific names of the 73 species are given in Table 2 and not repeated in the main text.)

Inevitably, in several families the 100 kilogram limit is somewhat arbitrary from an ecological perspective, and similar issues of conservation and international law can and do arise regarding slightly lighter herbivore species. To draw the line somewhere, however, it appears sensible to focus on the same species as Ripple et al. (2015) - just as Trouwborst (2015) focused on the same species as Ripple et al. (2014) — bearing in mind that the analysis below may also be relevant for (lighter) herbivores not appearing in Table 2.

The focus of this analysis is confined to legal instruments which (1) have as aim the conservation or sustainable use of nature (whether particular species, sites, ecosystems or biodiversity at large), and (2) the scope of which covers one or more of the 73 large herbivore species, whether explicitly or implicitly. The text and context of the various 


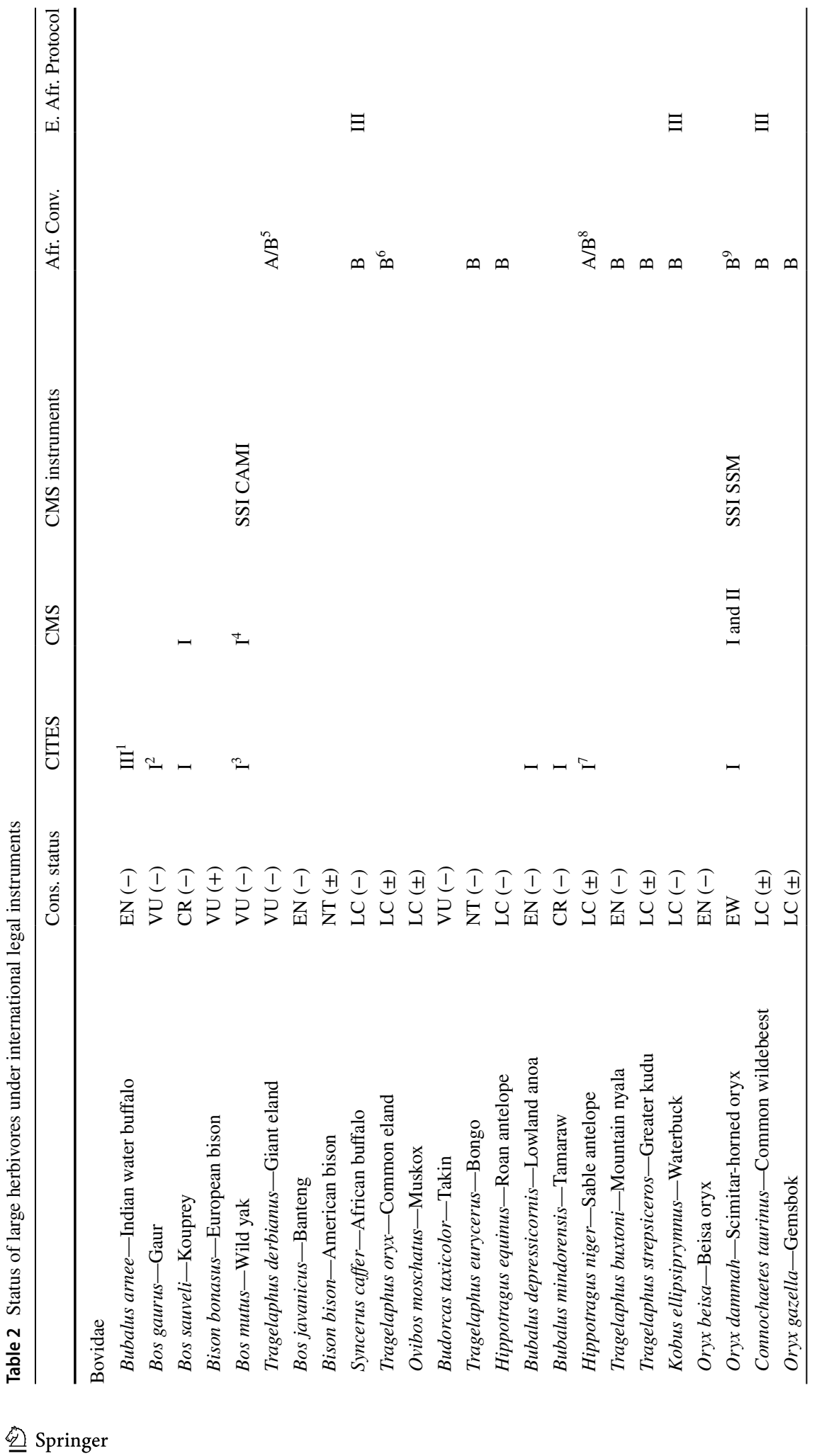




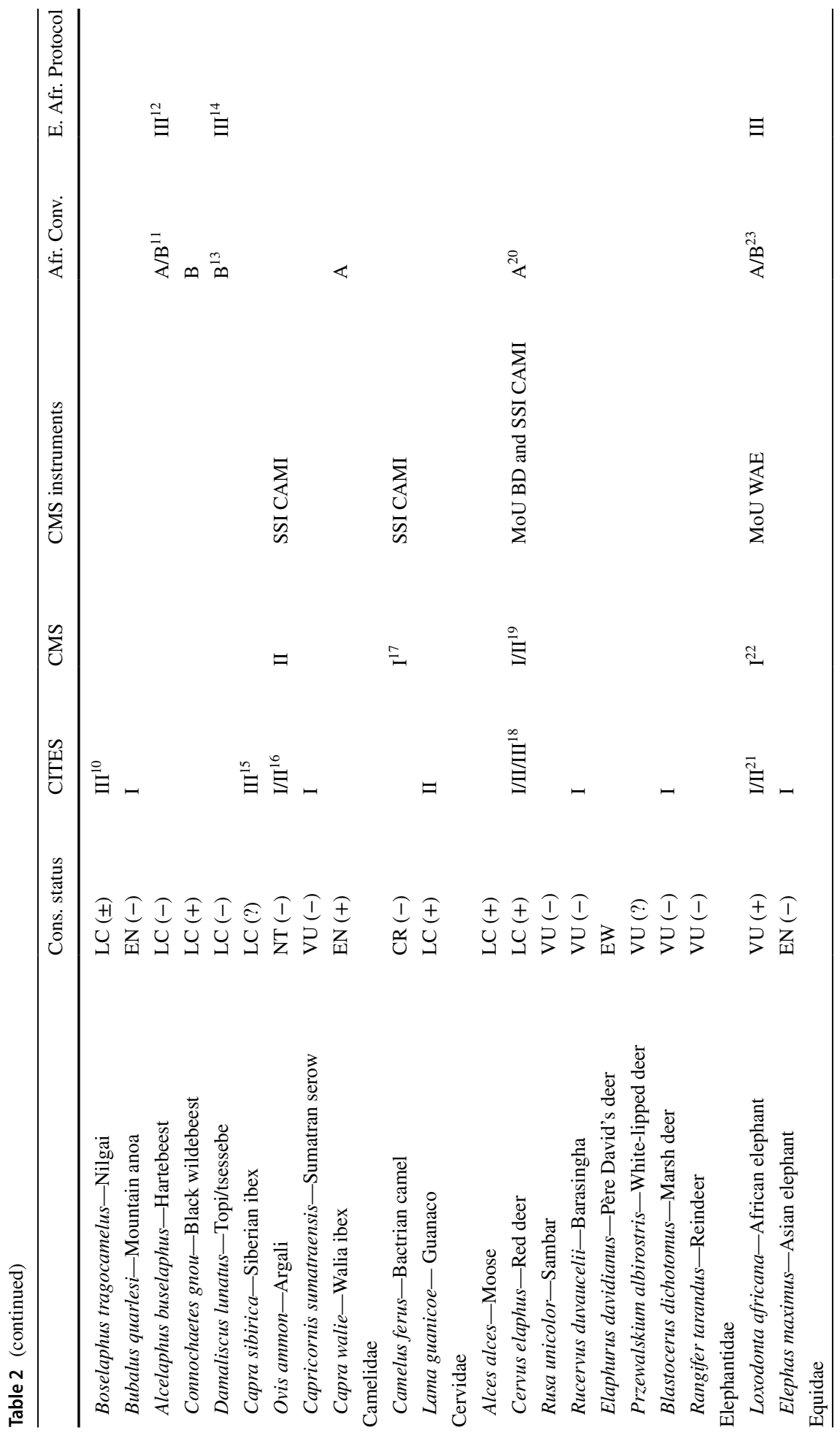




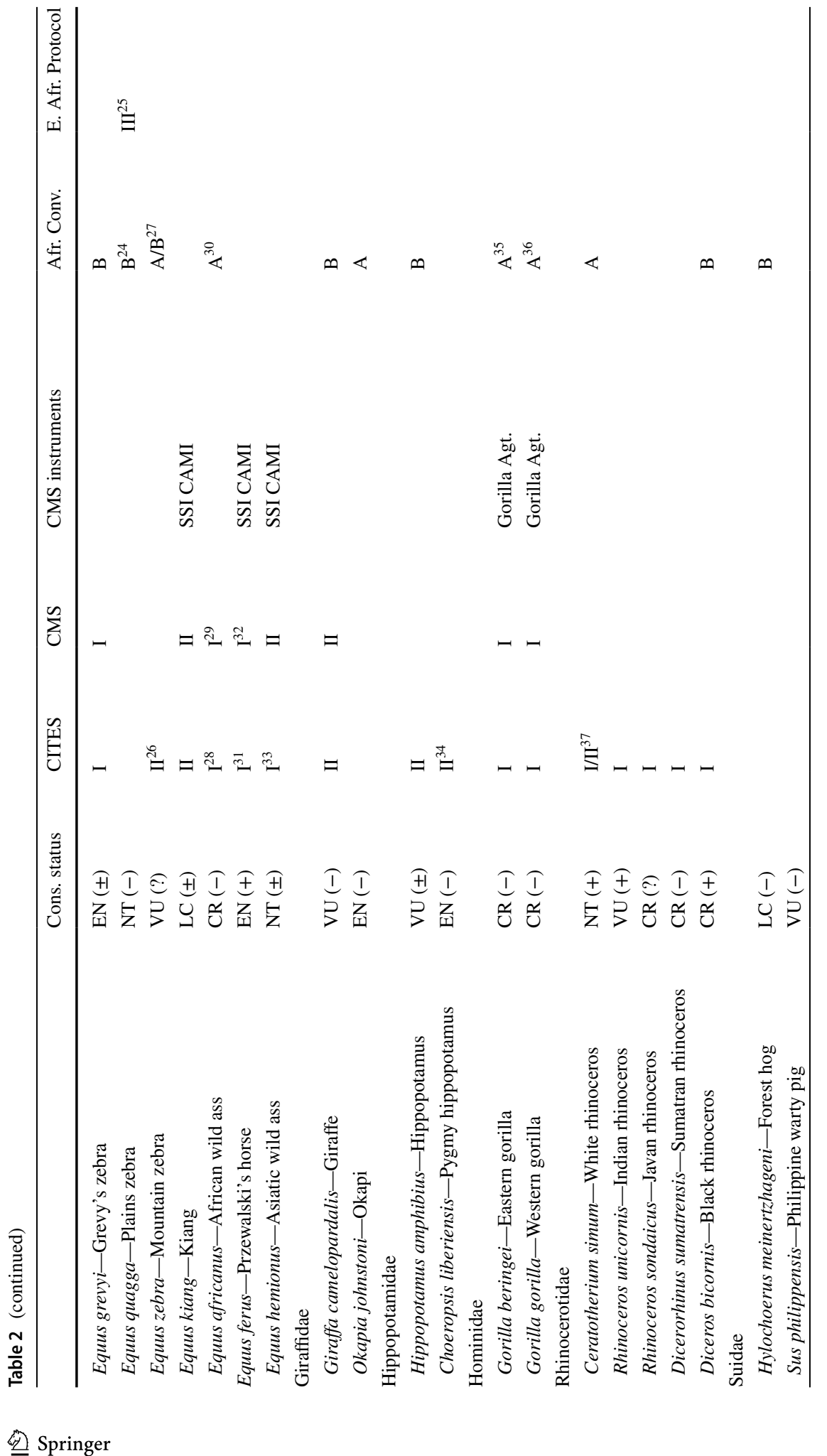




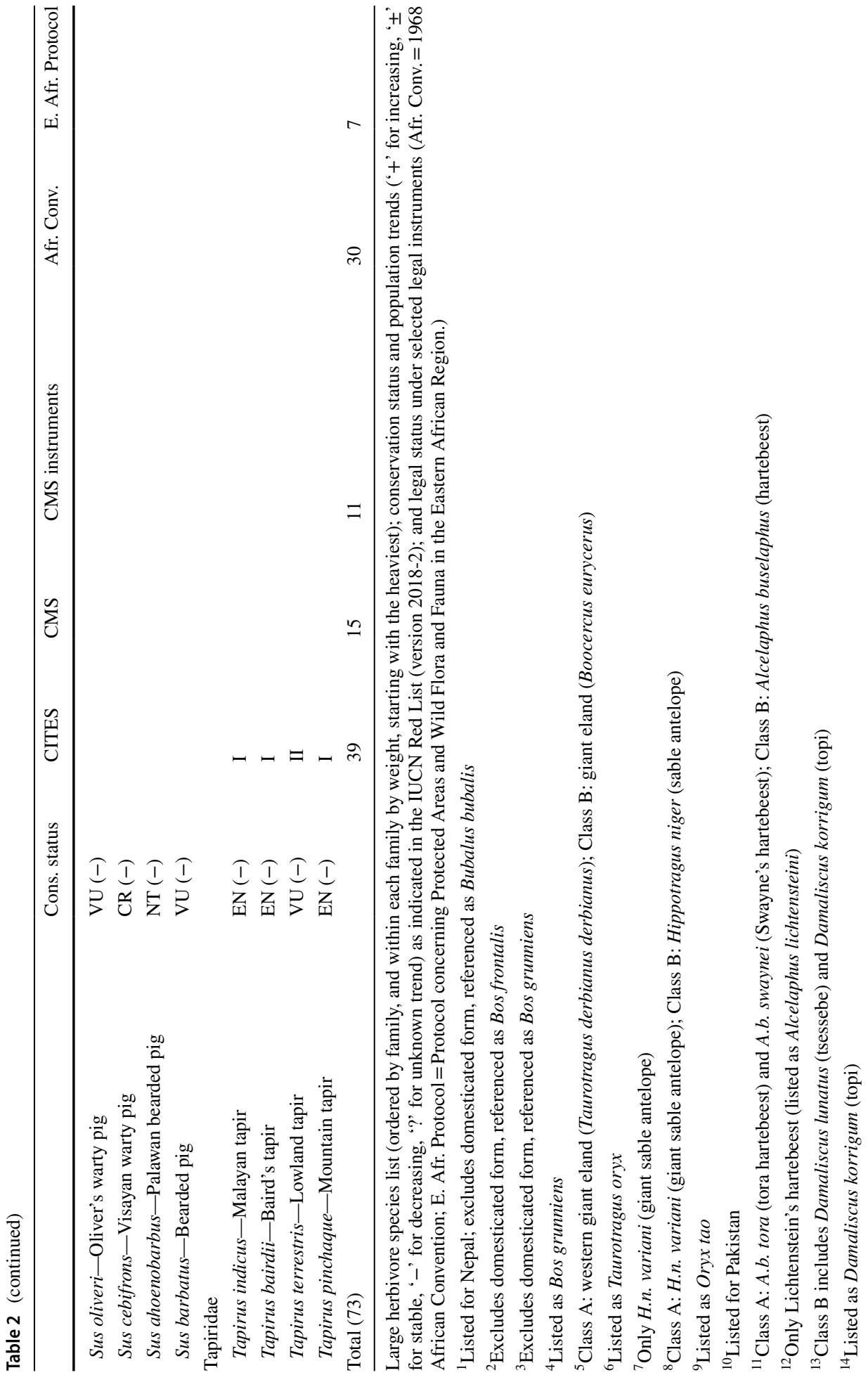




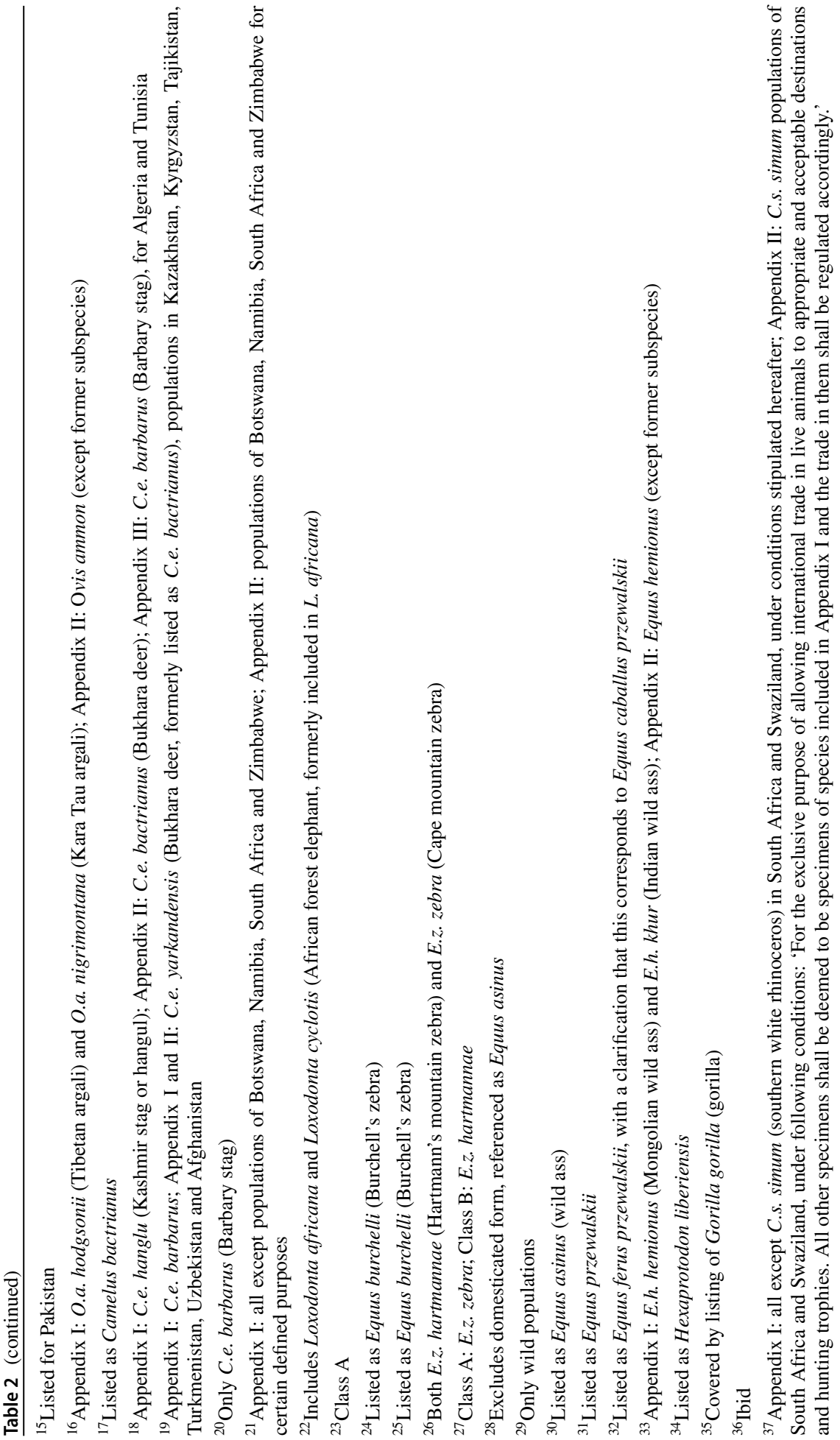


legal instruments can be encountered inter alia in databases like ECOLEX (http://www. ecolex.org) and the University of Oregon's International Environmental Agreements Database (http://iea.uoregon.edu), and in most cases on dedicated websites run by treaty administrators.

While identifying and illustrating the relevance of various legal instruments for large herbivore conservation, no detailed descriptions of the actual legal obligations of contracting parties, institutional structures, general functioning and overall conservation benefits of the various treaty regimes are given below, to avoid undue repetition. A possible starting point when looking for such detail is Trouwborst (2015), discussing most of the instruments mentioned below with respect to large carnivores; other suggested sources are Bowman et al. (2010, 2016), Gillespie (2011), Trouwborst et al. (2017b), and Janssens and Trouwborst (2018).

\section{Results and discussion}

\section{Surveying the legal landscape for large herbivore conservation}

A wide range of global, regional and bilateral legal instruments is presently of relevance to large herbivore conservation (Table 1). Some of these take a site-specific approach, such as the 1971 Convention on Wetlands of International Importance (Ramsar Convention), the 1972 World Heritage Convention (WHC), and treaties establishing transboundary conservation areas. Other treaties take a more species-specific approach, such as the 1973 Convention on International Trade in Endangered Species (CITES) and the 1979 Convention on Migratory Species (CMS). Various regional instruments reflect a combination of both approaches.

Several instruments employ species lists (appendices, annexes), with particular legal regimes associated with each. Such instruments are listed in Table 2. 39 of the 73 large herbivore species appear in CITES' appendices, and 15 are listed under the CMS (Table 2). Of the 32 African large herbivores, 30 are listed under the 1968 African Convention on the Conservation of Nature and Natural Resources, and some of these (7) are also listed under the 1985 Protocol concerning Protected Areas and Wild Flora and Fauna in the Eastern African Region (East Africa Protocol) (Table 2). A few species are covered by two European instruments not mentioned in Table 2. The 1979 Convention on the Conservation of European Wildlife and Natural Habitats (Bern Convention) lists European bison (Appendix III), muskox (II) and Corsican red deer Cervus elaphus corsicanus (II). The European Union's 1992 Directive on the Conservation of Natural Habitats and of Wild Fauna and Flora covers European bison (Annexes II and IV), Corsican red deer (II and IV) and Finnish forest reindeer Rangifer tarandus fennicus (II).

Although Table 2 can function as a quick reference concerning the international legal status of the various species, by itself it does not appear to justify many conclusions of general application. The table is best interpreted through a context-specific approach, paying attention to the specific features of species, legal instruments and countries involved (Trouwborst 2015). In addition, it should be borne in mind that Table 2 is confined to species-listing treaties. Thus, although the Sus species score blanks and the Tapiridae and Asian rhinos are only CITES-listed, they can still (and some do) profit from protection offered to their habitat under the Ramsar or World Heritage Conventions (see below), 
or benefit from some regional instrument (e.g., the Baird's tapir and the 1992 Central American Convention for the Conservation of Biodiversity and the Protection of Priority Wetlands).

A general conclusion that can nevertheless be drawn is that the international legal landscape for large herbivore conservation is rather complex (see Table 2's footnotes), and evidently not a very systematic or entirely consistent whole. Likewise, a large herbivore's conservation status and population trend are apparently not neat predictors of the degree to which it will be covered by international legal instruments. These general observations resonate with the outcome of the earlier global analysis of international law regarding large carnivores (Trouwborst 2015).

In addition, certain gaps and other concrete features of Table 2 are worth noting. For instance, whereas Africa and Europe are covered comparatively well, some parts of the world lack regional, species-targeting conservation treaties altogether. On a different level, the 1968 African Convention lacks an institutional structure and its species lists have not been updated since its adoption. To illustrate, the pygmy hippopotamus is not listed, and the white rhinoceros remains subject to stricter protection (Class A) than the black (Class B), even if this no longer mirrors their respective conservation status. Furthermore, the coverage of species by the CMS seems the result of a process that is less consistent than, for instance, the CITES listing process. CITES' appendices appear to include all large herbivore species which are substantially affected by international trade. Under the CMS, however, it is not immediately obvious, for instance, why the African elephant has been listed but not the Asian elephant, or why the wild yak is included but not the gaur.

\section{Limitations and potential}

When contemplating these and other questions regarding the adequacy of the international legal framework for large herbivore conservation, account should be taken of the nature of international law and politics. On the one hand, treaty obligations are legally binding, but on the other, such obligations are entered into (or not) by governments voluntarily, often after lengthy negotiations, rather than imposed and enforced top-down. In that sense, when compared to national legal systems, treaty law is more reminiscent of contracts (private law) than legislation (public law). Furthermore, decision-making within wildlife treaty frameworks can be influenced at least as much by political agendas as by ecological considerations, and knowledge gaps in combination with disagreement over values, ethics and legitimacy can further impede treaties' effective application (Wiersema 2015; Redpath et al. 2017; Bauer et al. 2018; Janssens and Trouwborst 2018). These features of international law account, at least partly, for the profuse country-specific arrangements and exceptions (see Table 2's footnotes), and for the fact that not all relevant countries are parties to all relevant treaties. To offer one illustration, the significance of the CMS for Bactrian camel conservation is currently limited by the absence of China as a contracting party.

When applying the various treaty obligations, not only their correct legal interpretation matters - e.g., duly distinguishing between obligations of effort and result-but also their appropriate translation towards particular national and local cultural and socio-economic contexts, and meeting the challenge of striking a proper balance between participatory, bottom-up approaches and top-down legislation (Dickman et al. 2015; Treves et al. 2015; Redpath et al. 2017; Hodgetts et al. 2018). Important limitations result, furthermore, from capacity shortages, corruption and other governance problems, which are especially prevalent in developing countries-where most (threatened) large herbivore species 
remain - and which can radically impair states' compliance with their wildlife treaty obligations (Bowman et al. 2010; Wandesforde-Smith 2016; Selier et al. 2016; Chapron et al. 2017; Felbab-Brown 2017; Trouwborst et al. 2017a; Hodgetts et al. 2018).

The above considerations should rightly temper one's expectations of international wildlife law, both in general and regarding large herbivores. In addition, quantifying treaties' contributions to large herbivore conservation in a comprehensive and accurate manner seems virtually impossible, due to the difficulty of disentangling the influence of individual treaties from the many other factors which can impact conservation status. Nonetheless, as illustrated below, the evidence available does suggest that international law is a conservation tool of significance, and that the predicament of many large herbivore species would be worse without it. Conservation benefits for large herbivores can and have resulted from international wildlife treaties in many different ways, including through (a) an enhanced priority of their conservation on governments' agendas; (b) the designation of protected areas benefitting large herbivores and (c) the adoption of national legislation regulating their use pursuant to treaty obligations; (d) providing institutional backing and continuity to international conservation plans; (e) the incorporation of concrete technical and other guidance issued by treaty bodies into national legislation and action plans; (f) assistance to conservation efforts through treaties' funding mechanisms; (g) augmented cooperation between stakeholders, both governmental and non-governmental; (h) coordinated collection and sharing of data; and (i) various cases in which detrimental activities were halted or specific conservation actions taken after governments were confronted with their international obligations in national or international court proceedings or compliance mechanisms (Bowman et al. 2010; Gillespie 2011; Trouwborst 2015; Bowman 2016; Scott 2016; Trouwborst et al. 2017a; Janssens and Trouwborst 2018). On balance, it appears that there can indeed be merit in measured and well-informed efforts to optimize the contribution of wildlife treaties to large herbivore conservation (Bowman 2016).

Against the backdrop of these overall considerations, the relevance of certain legal instruments for large herbivore conservation is examined slightly more closely below. Incidentally, it should be recalled that Table 1 only includes legal instruments with a nature conservation focus, and that additional instruments can directly or indirectly affect large herbivore conservation, for instance treaties concerned with climate change, pollutants, watercourses, or desertification.

\section{Ramsar Wetlands Convention}

The Ramsar Convention aims to halt and reverse the degradation and loss of wetlands around the world. The obligations of the Convention's 170 parties are geared towards the conservation and wise use of wetlands, with an emphasis on sites included in the List of Wetlands of International Importance. This List presently includes over 2300 sites of widely varying sizes, totaling a surface area of over 250,000,000 ha. 'Wetlands' as defined in the Convention - 'areas of marsh, fen, peatland or water, whether natural or artificial, permanent or temporary, with water that is static or flowing, fresh, brackish or salt' [Article 1(1)]—cover significant and sometimes essential portions of large herbivore habitat, whereby it should be noted that many of the larger sites on the List also include dry areas within their boundaries.

According to the Convention's listing criteria, a wetland should be considered internationally important inter alia if it supports 'vulnerable, endangered, or critically endangered species'; supports 'species important for maintaining the biological diversity of a particular biogeographic region'; supports species 'at a critical stage in their life cycles' or provides 
'refuge during adverse conditions'; and/or 'regularly supports $1 \%$ of the individuals in a population of one species or subspecies of wetland-dependent ... animal species' [Ramsar COP Resolution VII.11 (1999), last amended by Resolution X.20 (2008)]. Barasingha, marsh deer, hippopotamus, pygmy hippopotamus and Baird's tapir are clearly 'wetlanddependent' species in the sense of the fourth mentioned criterion (STRP and SSC 2006), whereas the other criteria imply many more large herbivore species. For instance, the Ramsar Convention has had a modest but tangible influence on the conservation of several rhinoceros species, by safeguarding some key habitat, and through concrete actions undertaken in the context of Ramsar site management plans (Janssens and Trouwborst 2018). An example is the control of alien plants threatening native food plants of Indian rhinoceros in Nepal's Beeshazar and Associated Lakes Ramsar site (Government of Nepal 2014).

In fact, many sites on the Ramsar List have been expressly designated partly or particularly for, or otherwise host, one or more of the 73 large herbivore species. An illustrative sample of listed wetlands around the world with the large herbivores they harbor is provided in Table 3. These range from the huge 5,537,400 ha Okavango Delta System, inhabited by 15 large herbivore species, to the modest 12,000 ha Nalsarovar Bird Sanctuary in India, which is nevertheless crucial for a satellite population of Indian wild ass Equus hemionus khur, which relies on the wetland in the dry season.

Besides the evident importance of the Ramsar Convention with regard to habitat conservation, it also has implications for the exploitation of large herbivores. For example, the Conference of the Parties (COP) has agreed that any harvesting of wildlife from listed sites must be sustainable, and regulated by a management plan developed by the party involved in close consultation with relevant stakeholders [Ramsar COP Resolution VII.19 (1999)].

Incidentally, and unsurprisingly, several Ramsar sites with large herbivores are also home to large carnivores, constituting ecological complexes of importance to megafauna and biodiversity conservation generally. To illustrate this point with reference to some of the sites in Table 3, Polar Bear Pass hosts wolves and polar bears Ursus maritimus in addition to reindeer and muskoxen; a guild of seven African large carnivores complements the Okavango's suite of large herbivores; the also huge Pantanal Boliviano features marsh deer and lowland tapirs alongside maned wolves Chrysocyon brachyurus, jaguars Panthera onca, pumas Puma concolor and giant otters Pteronura brasiliensis; and in Sembilang National Park, sambars, Asian elephants, bearded pigs and Malayan tapirs are still complemented with Sumatran tigers Panthera tigris sondaica, Sunda clouded leopards Neofelis diardi and sun bears Helarctos malayanus (Trouwborst 2015).

\section{World Heritage Convention}

The way the WHC benefits large herbivores (alongside large carnivores) is broadly comparable to the Ramsar Convention. The scope of the WHC is obviously not limited to wetlands, but it is restricted to sites of 'outstanding universal value'. Other differences are the stricter formulation of WHC parties' obligations regarding the conservation of natural heritage, the highly selective procedure for adding sites to the World Heritage List, and the associated prestige of such listing. 'Natural heritage' as defined in the Convention encompasses areas constituting the 'habitat of threatened species' which are deemed of 'outstanding universal value from the point of view of science or conservation', as well as 'natural areas of outstanding universal value from the point of view of science, conservation or natural beauty' (Article 2). 


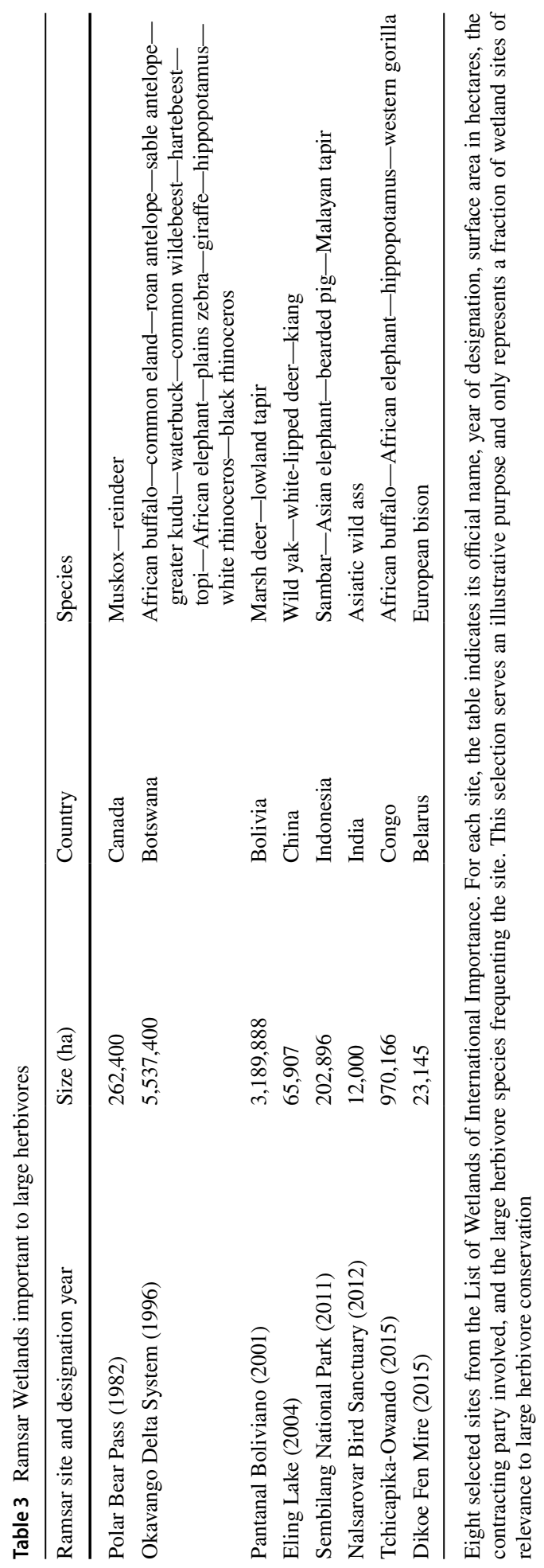


The World Heritage List indeed features numerous areas that are important to a wide range of large herbivores (see Table 4 for an illustrative selection). A prime example is Serengeti National Park, scene of the largest concentration of ungulates and one of the largest remaining unaltered large herbivore migrations in the world. To illustrate the WHC's added value, the Serengeti's World Heritage status was instrumental in a set of rulings by the East Africa Court of Justice against the upgrading of a road through the area into a 'super highway' [Ref. No. 9 of 2010 (20 June 2014); Appeal No. 3 of 2014 (29 July 2015)]. By way of another example, World Heritage status has also helped safeguard the key hippopotamus breeding grounds of Kenya's Lake Turkana National Parks site from oil exploration (World Heritage Centre 2015), although fresh threats from an Ethiopian dam project have prompted the site's recent inclusion in the List of World Heritage in Danger [World Heritage Committee Decision 42 COM 7B.92, 2018]. Likewise, a key role is reserved for the WHC in rhinoceros conservation, especially concerning the Asian species-for instance, the Ujung Kulon World Heritage site is the only place where Javan rhinos remain (Janssens and Trouwborst 2018). And all Walia ibex live in Ethiopia's Simien National Park, also World Heritage-listed.

Many World Heritage sites are also of significant conservation value at the subspecies level. Examples from Table 4 include Okapi Wildlife Reserve (forest buffalo Syncerus caffer nanus, forest elephant Loxodonta africana cyclotis); Golden Mountains of Altai (Altai argali Ovis ammon ammon, Altai wapiti Cervus elaphus sibiricus, forest reindeer Rangifer tarandus valentinae); and Tropical Rainforest Heritage of Sumatra (Sumatran elephant Elephas maximus sumatranus). Incidentally, similar considerations apply regarding Ramsar Wetlands.

\section{CITES}

CITES is another highly relevant treaty for large herbivore conservation, covering 39 of the 73 species (Table 2). Some of the most complex and controversial developments in CITES history revolved, and continue to revolve, around large herbivores, particularly elephants and rhinos, as documented extensively elsewhere (e.g., Glennon 1990; Kidd and Cowling 2003; Wiersema 2013; Couzens 2014; Wandesforde-Smith 2016; Coetzee and Couzens 2017; Janssens and Trouwborst 2018).

CITES Appendix I includes (populations or subspecies of) 28 large herbivore species, international commercial trade in which is in principle prohibited. Appendix II includes (populations or subspecies of) eleven large herbivore species, for which commercial trade is allowed but must be limited to sustainable levels. Appendix III, listing species for which individual parties have asked other parties' assistance in controlling trade, includes (populations or subspecies of) four large herbivore species (Table 2). Four species are split-listed across various appendices, and many more are subject to diverse annotations, meaning that careful reading is required to determine CITES' precise scope of application for the species involved (Table 2, footnotes). For example, most red deer are not subject to CITES provisions, but some subspecies are, Kashmir stag Cervus elaphus hanglu being on Appendix I, Bukhara deer C.e. bactrianus on Appendix II, and Barbary stag C.e. barbarus on Appendix III for Algeria and Tunisia. Whereas such listing flexibility is useful with a view to reflecting differences in conservation status and trade impacts across subspecies and countries, it also illustrates one of CITES' Achilles' heels, namely the practical difficulty faced by customs officials of distinguishing between very similar specimens which are nevertheless subject to different legal regimes (Bowman et al. 2010; Couzens 2014; Wandesforde-Smith 


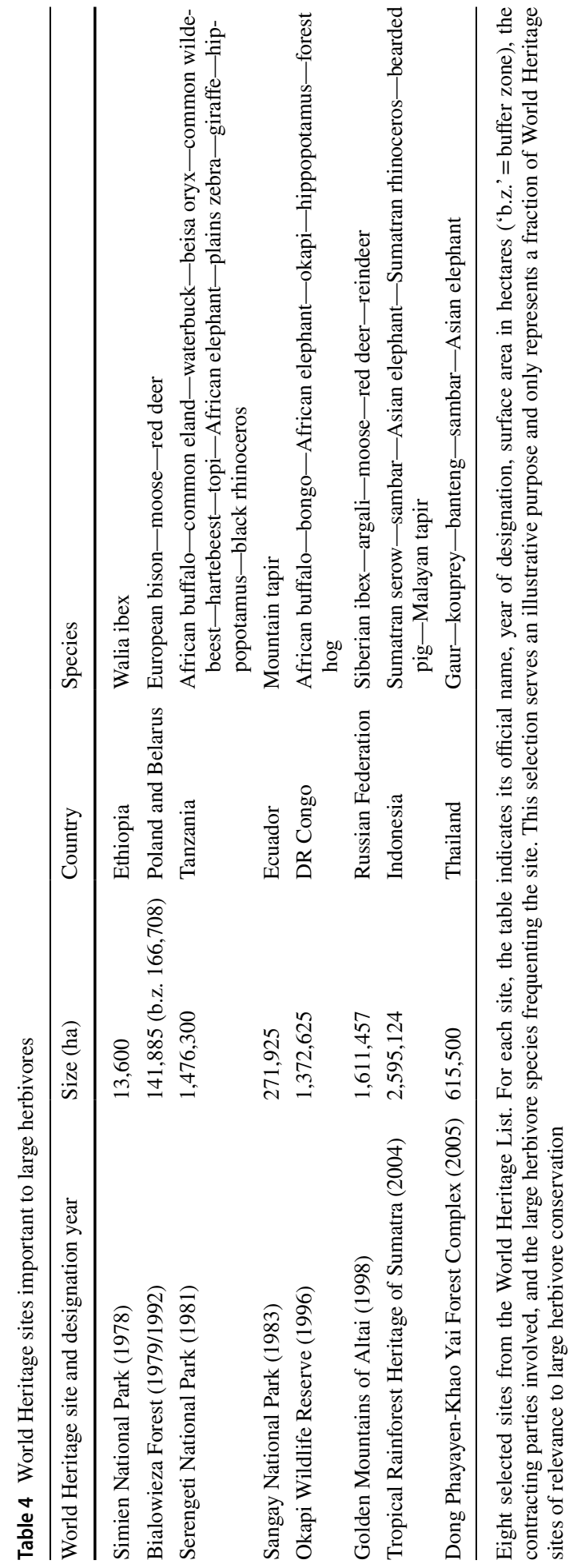


2016). Listing decisions concerning Appendices I and II are made by the COP, based on agreed biological and trade criteria [CITES Resolution Conf. 9.24 (Rev. CoP17)], but often with politics mixed in (e.g., Couzens 2014; Wiersema 2015; Bauer et al. 2018).

The guanaco is one large herbivore to whose conservation CITES appears to have contributed, by integrating international trade regulation with community-based natural resource management initiatives (Lichtenstein 2011). Some recent listing decisions have likewise been of a hopeful kind, with the 17th COP (in 2016) deleting wood bison Bison bison athabascae from Appendix II, and downlisting Cape mountain zebra Equus zebra zebra from Appendix I to II, following improvements in conservation status. And at its most recent meeting (COP18 in 2019), the COP agreed on an increase of South Africa's export quota for black rhinoceros hunting trophies to $0.5 \%$ of the country's population [COP18 Prop.48]. In contrast, certain other developments concerning large herbivores at COP18 illustrate shortcomings in the Convention's operation. Besides reports of continuing illegal trade, these include several mutually conflicting proposals regarding African elephant and white rhinoceros, reflecting a persistent divide between CITES parties regarding the way forward for these megaherbivores, and an increasing frustration of southern African range states with stable or increasing populations (IISD 2019). Moreover, several COP18 decisions were taken in apparent violation of the COP's own guideline to base decisions on the best scientific information available, notable examples being the giraffe's listing in Appendix II, and the COP's refusal to allow a modest relaxation of trade restrictions for white rhinoceroses from Namibia (IUCN/TRAFFIC 2019). Incidentally, COP18 also saw an (unsuccessful) proposal to list a long extinct megaherbivore, the woolly mammoth Mammuthus primigenius, with a view to look-alike issues involving elephant ivory [COP18 Prop.13].

\section{CMS and subsidiary instruments}

The CMS aims for the conservation of 'migratory species' and fosters cooperation between range states to that end. The term 'migratory species' has been interpreted by the CMS COP in a rather flexible manner, as encompassing practically all species with ranges straddling more than one country and members of which are therefore involved in the crossing of international jurisdictional boundaries (Bowman et al. 2010; Lewis and Trouwborst 2017). This approach has enabled the inclusion in the CMS appendices of species like gorillas, in addition to species that are migratory in a more classical sense.

CMS Appendix I lists 'migratory species which are endangered'. Parties that are range states of these species are required to implement certain conservation measures, including a broad prohibition on killing, capturing and harassing of individual animals, subject to a narrowly construed exceptions clause (Bowman et al. 2010; Trouwborst 2014). Presently, this Appendix I regime concerns 11 large herbivore species, i.e., three bovids, three equids, Bactrian camel, African elephant, certain red deer subspecies, and the western and eastern gorilla (Table 2). Of these, African wild ass and Przewalski's horse were added most recently, in 2017. It should be noted that not all range states of the large herbivores in Appendix I are amongst the current 127 CMS parties.

Appendix II lists migratory species with an unfavourable conservation status and/or which are likely to benefit from international cooperation. Range states of Appendix II species are expected to conclude and implement tailor-made agreements to further the species' conservation. Such subsidiary instruments may cover one or more species, part or all of the species' range(s), and take any of various shapes, with principal options including 
a binding treaty, a non-binding memorandum of understanding, and a so-called Special Species Initiative (SSI). Incidentally, CMS subsidiary instruments may also be adopted for non-listed species, and participation can be open to non-CMS parties. Six of the 73 large herbivore species are presently (partly or wholly) included in Appendix II (Table 2), the giraffe being the latest addition in 2017. It is not uncommon for species to be listed on both appendices, and the scimitar-horned oryx and Bukhara deer have such a double status.

Of the 15 CMS-listed large herbivores, 11 are presently covered by subsidiary instruments. These are one binding treaty (for gorillas), two memoranda of understanding (for elephants in West Africa and Bukhara deer), and two SSIs, for Sahelo-Saharan megafauna and Central Asian mammals (see Tables 1,2). To briefly illustrate one of them, the Central Asian Mammals Initiative (CAMI) is a flexible, cooperative arrangement involving governmental and nongovernmental stakeholders and targeting a species ensemble presently comprising 13 herbivores, including seven of the large herbivore species that are the focus of this analysis (Table 2), and two carnivores (cheetah and snow leopard Uncia uncia). The CAMI was launched by the CMS COP in 2014, along with a concrete Programme of Work, a set of Guidelines for Addressing the Impact of Linear Infrastructure on Large Migratory Mammals in Central Asia, and a Single Species Action Plan for the Conservation of the Argali [CMS Resolution 11.24].

\section{Other instruments}

Investing in the effective application of any of the aforementioned instruments would appear to be worthwhile from a megafauna conservation perspective.

Highlighting a selection of legal instruments, as just done, carries the risk of causing the impression that other instruments are unimportant. In the present context, such an impression would be erroneous. The $\mathrm{CBD}$ and a range of regional and bilateral treaties have their own, not necessarily less significant, roles to play. A case in point is the 2011 KavangoZambezi Transfrontier Conservation Area Treaty which established, and guides the development of, a vast conservation area stretching across five countries and sheltering at least $50 \%$ of all African elephants, and countless other large herbivores. For further introductions regarding the $\mathrm{CBD}$, the Algiers and Maputo Conventions, the SADC Protocol, the Bern Convention and other relevant instruments (Table 1), the reader is however kindly directed to other sources, including the literature mentioned in the methods section above.

A brief exception is justified for the East Africa Protocol, as it expressly covers seven large herbivores and the latter literature does not address it. The geographic scope of this protocol to the 1985 Nairobi Convention for the Protection, Management and Development of the Marine and Coastal Environment of the Eastern African Region includes parties' 'coastal areas' and 'internal waters related to the marine and coastal environment' [Article 1(a)]. Parties, which include Kenya, Tanzania, Mozambique and South Africa, are required inter alia to establish and conserve protected areas in order to safeguard the region's 'essential' ecological and biological processes; '[r]epresentative samples of all types of ecosystems'; and '[p]opulations of the greatest possible number of species of fauna and flora depending on these ecosystems' [Article 8(2)]. In addition, they 'shall take all appropriate measures to ensure the protection' [Article 5(1)] of species from Annex III, which lists '[h]arvestable species of wild fauna requiring protection' and includes African buffalo, waterbuck, common wildebeest, Lichtenstein's hartebeest, topi, African elephant and plains zebra. Any exploitation of these species 'shall be regulated in order to restore and 
maintain the populations at optimum levels', and management plans must be adopted and implemented to that end [Article 5(2)].

\section{Outlook: meeting obligations and avoiding empty landscapes}

Ripple et al. (2015, p. 9) ended with these observations: 'Large herbivores, and their associated ecological functions and services, have already largely been lost from much of the developed world. The scale and rate of large herbivore decline suggest that without radical intervention, large herbivores (and many smaller ones) will continue to disappear from numerous regions with enormous ecological, social, and economic costs. We have progressed well beyond the empty forest to early views of the "empty landscape" in desert, grassland, savanna, and forest ecosystems across much of planet Earth.'

The interventions required to fend off this empty landscape scenario ultimately boil down to providing large herbivores with large enough areas of suitable habitat (whether or not shared with humans), in which they are either protected or used in a sustainable manner (Macdonald et al. 2013; Ripple et al. 2015). Wildlife treaties and intergovernmental cooperation have a role to play in this regard, as the preceding analysis attests.

Protected areas are a key feature of many treaties. The Ramsar Convention's contribution to wetland conservation, for instance, is particularly significant in light of the global tendency to locate protected areas in low-quality habitats (Joppa and Pfaff 2009). The World Heritage Convention similarly casts a protective shadow over some of the world's most important remaining megafauna habitat. Likewise, CITES, despite its limitations, remains the principal framework for steering the influence of international trade away from overexploitation and towards sustainable use of large herbivores. Furthermore, the CMS and its subsidiary instruments, and several regional treaties, have contributed tangibly to large herbivore conservation efforts around the globe. The CBD too is likely to have had positive impacts, mostly indirectly, inter alia through the instigation of national biodiversity strategies and action plans.

Yet, all of this has not been enough to stem the tide, for a familiar amalgamation of reasons outlined above. For example, given large herbivores' current plight and substantial space requirements, the international community's terrestrial protected area target should be set significantly higher than the CBD's current 17\% (Ripple et al. 2015) - and then attained as soon as possible, by conserving the necessary areas 'through effectively and equitably managed, ecologically representative and well connected systems of protected areas, and other effective area-based conservation measures', to use the wording agreed on by virtually all the world's governments when adopting Aichi Target 11 [CBD COP Decision X/2, 2010]. In large herbivore habitat in the broader landscape beyond protected areas, land-sharing and sustainable use-two notions which are already broadly endorsed in international wildlife law (Cretois et al. 2019)—ought to become the leading paradigms shaping human activity.

Ripple et al. (2015, p. 9) also called for a 'global government-funded scheme for rare large herbivores beyond elephants and rhinoceros'. If such a scheme were to be linked to or embedded within an existing intergovernmental framework for biodiversity conservation, the CMS would appear the most likely candidate in terms of scope, institutional structure and experience, and current and potential species coverage. At present, however, the CMS regime operates on very limited budgets. For the Convention and its subsidiary instruments to be implemented in a manner that would achieve their own goals of attaining and 
maintaining a favourable conservation status for the many species involved, requires finding the right balance between participatory approaches that are fine-tuned to local conditions, and adequate safeguards which ultimately ensure conservation results (Chapron et al. 2017; Redpath et al. 2017). The investments needed to do this, in turn, presuppose steeply increased and sustained funding (McCarthy et al. 2012; Lindsey et al. 2017, 2018). This appears true of wildlife treaties across the board. Many of these set out far-reaching, legally binding obligations of result, which can however only be met if governments invest the necessary funds. In line with the principle of 'common but differentiated responsibilities', as set out inter alia in the 1992 Rio Declaration on Environment and Development, most will be expected of the richest countries, in view of both the 'pressures their societies place on the global environment and of the technologies and financial resources they command' (Rio Declaration, Principle 7; see also Lindsey et al. 2017).

Overall, the outcome of the above analysis confirms the impression by Ripple et al. (2016, p. 811) that international wildlife treaties 'have had some success in safeguarding species' but that it will require 'substantially increased political will and financial support if they are to be effective in the critical task of securing the survival of the world's megafauna.' This is in line with the call for 'transformative changes' across economic, social, political and technological dimensions of human societies in the recent global assessment by the Intergovernmental Science-Policy Platform for Biodiversity and Ecosystem Services (IPBES 2019; Bridgewater et al. 2019). At the same time, the above analysis indicates that it remains worthwhile, even before such game-changing developments materialize, to seek and use the opportunities for large herbivore conservation within the current legal landscape. Avenues to do so include expanding, where appropriate, the scope of treaties and other legal instruments in terms of species, countries and sites covered; further clarifying their precise implications for large herbivore conservation; and, most of all, promoting the instruments' effective implementation. One way to pursue the latter is by increasing conservation professionals' awareness and understanding of the legal context in which they operate, and of the concrete tools and arguments that may be encountered in international wildlife law to bolster large herbivore conservation. It is hoped that the above analysis can help achieve this.

Acknowledgements Helpful comments by Guillaume Chapron, Marco Festa-Bianchet and an anonymous reviewer are gratefully acknowledged.

Open Access This article is distributed under the terms of the Creative Commons Attribution 4.0 International License (http://creativecommons.org/licenses/by/4.0/), which permits unrestricted use, distribution, and reproduction in any medium, provided you give appropriate credit to the original author(s) and the source, provide a link to the Creative Commons license, and indicate if changes were made.

\section{References}

Ayling J (2013) What sustains wildlife crime? Rhino horn trading and the resilience of criminal networks. J Int Wildl Law Policy 16:57-80

Bauer H, Nowell K, Sillero-Zubiri C, Macdonald DW (2018) Lions in the modern arena of CITES. Conserv Lett 11:e12444

Bowman MJ (2016) Law, legal scholarship and the conservation of biological diversity: 2020 vision and beyond. In: Bowman MJ, Davies PGG, Goodwin EJ (eds) Research handbook on biodiversity and law. Edward Elgar, Cheltenham, pp 3-54

Bowman M, Davies P, Redgwell C (2010) Lyster's international wildlife law, 2nd edn. Cambridge University Press, Cambridge 
Bowman MJ, Davies PGG, Goodwin EJ (eds) (2016) Research handbook on biodiversity and law. Edward Elgar, Cheltenham

Bridgewater P, Loyau A, Schmeller DS (2019) The seventh plenary of the Intergovernmental Platform for Biodiversity and Ecosystem Services (IPBES-7): a global assessment and a reshaping of IPBES. Biodivers Conserv 28:2457-2461

Cardillo M, Mace GM, Jones KE, Bielby J, Beninda-Emonds OR, Sechrest W et al (2005) Multiple causes of high extinction risk in large mammal species. Science 309:1239-1241

Chapron G, Epstein Y, Trouwborst A, López-Bao JV (2017) Bolster legal boundaries to stay within planetary boundaries. Nat Ecol Evol 1:0086

Cliquet A, Decleer K (2017) Halting and restoring species loss: incorporating the concepts of extinction debt, ecological trap and dark diversity into conservation and restoration law. Griffith Law Rev 26:178-201

Coetzee L, Couzens E (2017) Keeping the rhino (debate) alive: Swaziland's proposal at CITES CoP17 in 2016. S Afr J Environ Law Policy 23:217-254

Couzens E (2014) Whales and elephants in international conservation law and politics: a comparative study. Earthscan, Abingdon

Cretois B, Linnell JDC, Kaltenborn BP, Trouwborst A (2019) What form of human-wildlife coexistence is mandated by legislation? A comparative analysis of international and national instruments. Biodivers Conserv 28:1729-1741

Danell K, Bergström R, Duncan P, Pastor J (eds) (2006) Large herbivore ecology, ecosystem dynamics and conservation. Cambridge University Press, Cambridge

Dickman AJ, Hinks AE, Macdonald EA, Burnham D, Macdonald DW (2015) Priorities for global felid conservation. Conserv Biol 29:854-864

Epstein Y (2013) Population based species management across legal boundaries: the Bern Convention, Habitats Directive, and the gray wolf in Scandinavia. Georget Int Environ Law Rev 25:549-579

Felbab-Brown V (2017) The extinction market: wildlife trafficking and how to counter it. Hurst \& Company, London

Freyfogle E (2006) Conservation biology and law: only a start. Conserv Biol 20:679-680

Gillespie A (2011) Conservation, biodiversity and international law. Edward Elgar, Cheltenham

Glennon M (1990) Has international law failed the elephant? Am J Int Law 84:1-43

Government of Nepal (2014) Site management plan, Beeshazar and associated lakes (Ramsar site). http://ramsar.rgis.ch/pdf/wurc/Beeshazar-and-associated-Lakes-Management-Plan.pdf

Hodgetts T, Lewis M, Bauer H, Burnham D, Dickman A, Macdonald E et al (2018) Improving the role of global conservation treaties in addressing contemporary threats to lions. Biodivers Conserv 27:2747-2765

IISD (2019) Summary of the 18th meeting of the CITES Conference of the Parties: 17-28 August 2019. Earth Negot Bull 21:101

IPBES (2019) Summary for policymakers of the global assessment report on biodiversity and ecosystem services of the Intergovernmental Science-Policy Platform on Biodiversity and Ecosystem Services. https://www.ipbes.net/sites/default/files/downloads/spm_unedited_advance_for_posting_htn. pdf

IUCN/TRAFFIC (2019) IUCN and TRAFFIC analyses of the proposals to amend the CITES appendices at the 18th meeting of the Conference of the Parties. IUCN, Gland

Janssens B, Trouwborst A (2018) Rhinoceros conservation and international law: the role of wildlife treaties in averting megaherbivore extinction. J Int Wildl Law Policy 21:146-189

Joppa LN, Pfaff A (2009) High and far: biases in the location of protected areas. PLoS ONE 4:e8273

Jung BD (2017) The tragedy of the elephants. Wis Law Rev 695:737

Kidd M, Cowling M (2003) CITES and the African elephant. In: Chaytor B, Gray KR (eds) International environmental law and policy in Africa. Kluwer, Dordrecht, pp 49-63

Kimberley G (2017) International intent and domestic application of the Convention on International Trade in Endangered Species of Wild Fauna and Flora (CITES): the case of the ocelot (Leopardus pardalis). J Int Wildl Law Policy 20:253-294

Leader-Williams N, Milledge S, Adcock K, Brooks M, Conway A, Knight M et al (2005) Trophy hunting of black rhino Diceros bicornis: proposals to ensure its future sustainability. J Int Wildl Law Policy 8:1-11

Lewis M, Trouwborst A (2017) Bonn Convention on the Conservation of Migratory Species of Wild Animals 1979 (CMS). In: Fitzmaurice M, Tanzi A, Papantoniou A (eds) Encyclopedia of environmental law: multilateral environmental agreements. Edward Elgar, Cheltenham, pp 25-34

Lichtenstein G (2011) Use of vicuñas (Vicugna vicugna) and guanacos (Lama guanicoe) in Andean countries. Linking community-based conservation initiatives with international markets. In: 
Abensperg-Traun M, Roe D, O'Criodain C (eds) CITES and CBNRM. IUCN and IIED, Gland/ London, pp 103-108

Lindsey PA, Chapron G, Petracca LS, Burnham D, Hayward MW, Henschel P et al (2017) Relative efforts of countries to conserve world's megafauna. Glob Ecol Conserv 10:243-252

Lindsey PA, Miller JRB, Petracca LS, Coad L, Dickman AJ, Fitzgerald KH et al (2018) More than \$1 billion needed annually to secure Africa's protected areas with lions. PNAS 115:E10788-E10796

Linnell JDC, Trouwborst A, Fleurke FM (2017) When is it acceptable to kill a strictly protected carnivore? Exploring the legal constraints on wildlife management within Europe's Bern Convention. Nat Conserv 12:129-157

Macdonald DW (2019) Brushes with the law: a conservation scientist's perspective on legal solutions and impediments from Scottish wildcats to African lions. J Int Wildl Law Policy 22:1-32

Macdonald DW, Boitani L, Dinerstein E, Fritz H, Wrangham R (2013) Conserving large mammals: are they a special case? In: Macdonald DW, Willis KJ (eds) Key topics in conservation biology, vol 2. Wiley-Blackwell, Oxford, pp 277-312

McCarthy DP, Donald PF, Scharlemann JPW, Buchanan GM, Balmford A, Green JMH et al (2012) Financial costs of meeting global biodiversity conservation targets: current spending and unmet needs. Science 338:946-949

Moreno di Marco M, Boitani L, Mallon D, Hoffmann M, Iacucci A, Meijaard E et al (2014) A retrospective evaluation of the global decline of carnivores and ungulates. Conserv Biol 28:1109-1118

Nollkaemper A (2014) Framing elephant extinction. In: ESIL Reflections, vol 3

Nowell K, Rosen T (2018) Global cheetah conservation policy: a review of international law and enforcement. In: Marker L et al (eds) Cheetahs: biology and conservation. Academic Press, London, pp 291-305

Owen-Smith N (1989) Megaherbivores: the influence of very large body size on ecology. Cambridge University Press, Cambridge

Persaud S (2017) Losing our 'CITES' on the 'traffic': how taxing ivory trafficking can save the African elephant from its bloody extinction. J Int Wildl Law Policy 20:295-320

Redpath S, Linnell JDC, Festa-Bianchet M, Boitani L, Bunnefeld N, Dickman A et al (2017) Don't forget to look down: collaborative approaches to predator conservation. Biol Rev 92:2157-2163

Ripple WJ, Estes JA, Beschta RL, Wilmers CC, Ritchie EG, Hebblewhite M et al (2014) Status and ecological effects of the world's largest carnivores. Science 343:1241484

Ripple WJ, Newsome TM, Wolf C, Dirzo R, Everatt KT, Galetti M et al (2015) Collapse of the world's largest herbivores. Sci Adv 1:e1400103

Ripple WJ, Chapron G, López-Bao JV, Durant S, Macdonald DW, Lindsey PA et al (2016) Saving the world's terrestrial megafauna. Bioscience 66:807-812

Schipper J, Chanson JS, Chiozza F, Cox NA, Hoffmann M, Katariya V et al (2008) The status of the world's land and marine mammals: diversity, threat, and knowledge. Science 322:225-230

Scott KN (2016) Non-compliance procedures and the implementation of commitments under wildlife treaties. In: Bowman MJ, Davies PGG, Goodwin EJ (eds) Research handbook on biodiversity and law. Edward Elgar, Cheltenham, pp 414-436

Selier SAJ, Slotow R, Blackmore A, Trouwborst A (2016) The legal challenges of transboundary wildlife management at the population level: the case of a trilateral elephant population in southern Africa. J Int Wildl Law Policy 19:101-135

Snyder KD (2015) The common hippopotamus in the wild and in captivity: conservation for less charismatic species. J Int Wildl Law Policy 18:337-354

STRP (Ramsar Convention's Scientific and Technical Review Panel), SSC (IUCN Species Survival Commission) (2006) Population estimates and 1\% thresholds for wetland-dependent non-avian animal species, for the application of Criterion 9. Ramsar Convention. https://www.archive.ramsa r.org/pdf/ris/key_ris_criterion9_2006.pdf

Treves A, Chapron G, López-Bao JV, Shoemaker C, Goeckner AR, Bruskotter JT (2015) Predators and the public trust. Biol Rev 92:248-270

Trouwborst A (2014) Aussie jaws and international laws: the Australian shark cull and the Convention on Migratory Species. Cornell Int Law J Online 2:41-46

Trouwborst A (2015) Global large carnivore conservation and international law. Biodivers Conserv 24:1567-1588

Trouwborst A (2018) Wolves not welcome? Zoning for large carnivore conservation and management under the Bern Convention and EU Habitats Directive. Rev Eur Comp Int Environ Law 27:306-319

Trouwborst A, Fleurke FM, Dubrulle JSV (2016) Border fences and their impacts on large carnivores, large herbivores and biodiversity: an international wildlife law perspective. Rev Eur Comp Int Environ Law 25:291-306 
Trouwborst A, Blackmore A, Boitani L, Bowman M, Caddell R, Chapron G et al (2017a) International wildlife law: understanding and enhancing its role in conservation. Bioscience 67:784-790

Trouwborst A, Lewis M, Burnham D, Hinks A, Hodgetts T, Macdonald EA, Macdonald DW (2017b) International law and lions (Panthera leo): understanding and improving the contribution of wildlife treaties to the conservation and sustainable use of an iconic carnivore. Nat Conserv 12:83-128

Trouwborst A, Loveridge AJ, Macdonald DW (in press) Spotty data: managing international leopard (Panthera pardus) trophy hunting quotas amidst uncertainty. J Environ Law

Wandesforde-Smith G (2016) Looking for law in all the wrong places: dying elephants, evolving treaties, and empty threats. J Int Wildl Law Policy 19:365-381

Watts S (2016) Protection of the African lion: a critical analysis of the current international legal regime. Potchefstroom Electron Law J 19:6

Wiersema A (2013) Uncertainty and markets for endangered species under CITES. Rev Eur Comp Int Environ Law 25:239-250

Wiersema A (2015) Uncertainty, precaution, and adaptive management in wildlife trade. Mich J Int Law $36: 375-424$

World Heritage Centre (2015) UNESCO and IUCN welcome new no-go pledge for World Heritage sites by Tullow Oil. http://whc.unesco.org/en/news/1379

Publisher's Note Springer Nature remains neutral with regard to jurisdictional claims in published maps and institutional affiliations. 